\title{
12 haftalık pilates mat egzersizinin 14-15 yaş voleybol kız öğrencilerinin bazı biyomotor özellikler ve teknik performans üzerine etkilerinin incelenmesi
}

\section{İ. Canan DEMIR ${ }^{1}$, Murat ÇíLLí ${ }^{2}$}

\begin{abstract}
$\ddot{\mathbf{O z}}$
$\mathrm{Bu}$ çalışmada, pilates mat egzersizlerinin genç voleybolcularda kuvvet, dayanıklılık, sürat, patlayıcı kuvvet, süratte devamlılık, denge ve esneklik özellikleri ile teknik performansları üzerine etkilerinin incelenmesi amaçlanmıştır. Araştırmaya 14-15 yaşlarında 30 bayan voleybolcu gönüllü olarak katılmıştır. Rastgele seçimle sporculardan 15 'i deney grubu 15 'i kontrol grubunu oluşturmuşlardır. Deney grubu ve kontrol grubunun voleybol antrenman günleri, antrenman içerikleri ve saatleri aynı olmuştur, deney grubu ek olarak 12 hafta süreyle haftada iki saat pilates egzersizleri yapmışlardır. Sporcular egzersizlere başlamadan önce ön testler alınmış olup, on iki hafta sonunda son testler alınmıştır. Her iki test esnasında toplanan verilerin tanımlayıcı istatistikleri hesaplandıktan sonra, homojen veriler için two sample paired t-test, homojen olmayan veriler için Wilcoxon Signed Rank Test kullanılmıştır. Tüm istatistiklerdeki $\mathrm{p}$ anlamlılık değeri $\mathrm{p} \leq 0.05$ olarak alınmıştır. Kontrol gurubunda yer alan sporcuların kol hareket sürati, line drill, el kavrama kuvveti, sağlik topu atma ve mekik koşusu testlerinde istatistiksel olarak pozitif yönde anlamlı fark gözlenirken, denge testi, otur eris, omuz esneklik, durarak uzun atlama, dikey sıçrama aktif, dikey sıçrama pasif, bükülü kol asılma, 30 sn mekik testlerinde anlamlı bir fark gözlenmemiştir. Deney grubunda yer alan sporcuların biyomotor özelliklerinin ve teknik performanslarının tüm ön test son test değerleri arasında istatistiksel olarak pozitif yönde anlamlı farklılıklar oluştuğu gözlenmiştir. Deney ve kontrol gruplarında farklılık gözlenen parametrelerdeki gelişme yüzdeleri karşılaştırıldığında deney grubunda daha yüksek oranda gelişme olduğu belirlenmiştir. Teknik performans değerlerine bakıldığında deney ve kontrol grubu verilerinin hepsinde istatistiksel olarak pozitif yönde anlamlı fark bulunmuştur. Sonuç olarak, pilates mat egzersizlerinin biyomotor özelliklere ve teknik performansa olumlu yönde etkisi olduğu gözlenmiştir. Voleybolcularda pilates mat egzersizlerinin sporcuların biyomotor özelliklerinin geliştirilmesinde yararlar sağlayacağı düşünülmektedir.
\end{abstract}

Yayın Bilgisi

Anahtar Kelimeler: Pilates, Biyomotor, Teknik, Kuvvet, Dayanıklılık, Sürat, Denge, Esneklik, Sürratte devamlılık, Patlayıcı kuvvet, Performans

\section{Examination of the effect of 12 weeks Pilates mat exercises on some biomotor characteristics} and technical performance of 14-15 years old female volleyball students

İ. Canan DEMIR ${ }^{1}$, Murat ÇİLLí ${ }^{2}$

\begin{abstract}
The purpose of the study was to determine the effects of pilates mat exercises on young volleyball students; strength, endurance, speed, explosive force, speed continuity, balance and flexibility parameters and technical performances. 30 female 14-15 years old volleyball players participated voluntarily in this research. With random selection; 15 of the athletes are participated in experiment group, 15 of the athletes are participated in control group. The volleyball training days, training contents and hours of the exercises were the same in experiment group and the control group, additionally the experiment group had two pilates exercises per week and lasted twelve weeks in total. Preliminary tests were taken before the lessons started and after the lessons the final tests were taken. During both tests, after the descriptive statistics of the collected data were calculated, two sample paired t-test was used for homogenous data, Wilcoxon Signed Rank Test was used for nonhomogeneous data. The $p$-significance value in all statistics was taken as $p \leq 0.05$. In control group; there was a significant difference in arm movement speed, line drill, hand grip strength, health ball throwing and shuttle running tests but, there wasn't a significant difference in balance test, seat access, shoulder flexibility, standing jumping, vertical jumping active, vertical jumping passive, twisted arm $30 \mathrm{sn}$ crunch tests. When we look at the experiment group, there was a positive significant difference in biomotor characteristics and technical performance tests. When we compared the final tests of the significant data of the experiment and control groups, it was found that there was more relevance in the experiment group as $\%$. When the technical performance values were examined, positive significant differences were found in all of the experiment and control group data. In conclusion, pilates mat exercises were found to have a positive effect on biomotor characteristics and technical performance. It can be recommended that using pilates mat exercises are providing benefits in improving the
\end{abstract}

Article Info

Received:23.11.2017

Accepted:27.11.2017

Online Published:31.12.2017

DOI: $10.26453 /$ otjhs.364026

Corresponding Author

İ. Canan DEMİR 
biomotor properties of volleyball players.

Keywords: Pilates, Biomotor, Technique, Force, Endurance, Speed, Balance, flexibility, Continuity in Speed, Explosive Force, Performance

\footnotetext{
${ }^{1}$ Sakarya Üniversitesi, Sağlık Bilimleri Enstitüsü, Antrenörlük Eğitimi A.B.D., Yüksek Lisans Öğrencisi, Sakarya

${ }^{2}$ Sakarya Üniversitesi, Spor Bilimleri Fakültesi, Antrenörlük Eğitimi Bölümü, Sakarya

*Bu çalışma, İ. Canan DEMİR'in yüksek lisans tezinden üretilmiştir.
}

\section{GíRIȘ}

Pilates, birinci dünya savaşı sırasında Joseph Pilates tarafindan kasları güçlendirmek, esnekliği arttırmak ve vücudun genel sağlı̆̆ını iyileştirmek amacıyla geliştirilmiş bir egzersiz sistemidir. Pilates egzersizleri minder üzerinde ya da özel olarak tasarlanmış aletlerle yapılmaktadır. ${ }^{1}$ Fizyoterapistler tarafindan rehabilitasyon sürecinin bir parçası olarak sıklıkla kullanılan pilates metodu, fitness salonlarında ve pilates stüdyolarında özel eğitmenler eşliğinde yapılmaktadır. ${ }^{2}$ Pilates engelli bireyler dahil her yaştan insan tarafından rahatlıkla yapılabilmektedir. Duruş bozukluğu olanlar, esneklik kazanmak isteyenler ve kaslarını kalınlaştırmadan geliştirmek isteyenler tarafindan pilates uygulamaları yaygin olarak kullanılmaktadır. Amerika Birleşik Devletinde yapılan araştırmada 2016 yılında yaklaşık 9 milyon bireyin pilates egzersizlerine katıldığ 1 belirlenmiştir. $^{3}$

Gerçekleştirilen bir çok çalışmada pilates egzersizlerinin özellikle gövde kaslarının kuvveti $^{4,5,6}$, esneklik ${ }^{4,6-10}$, dayanıkl11ık performansi $1^{5,6,9-11}$ ve denge becerisi gelişimi ${ }^{6}$ üzerinde olumlu etkilerde bulunduğu gözlenmiştir. Artan kas kuvveti ile ilişkili olarak pilates egzersizlerinin kemik yoğunluğu üzerinde olumlu etkilerde bulunduğu gözlenmiştir. ${ }^{12}$ Ayrıca hamilelerde çeşitli nefes egzersizleriyle birlikte pilates egzersizlerinden yararlanılmaktadır. ${ }^{13} \mathrm{Ne}$ var ki gerçekleştirilen çalışmalarda genellikle pilates egzersizlerinin sedanter bireyler üzerindeki etkilerinin incelendiği gözlenmektedir. Öte yandan pilates egzersizlerinin sportif performansin geliştirilmesi amacıyla kullanımı yaygın değildir.

Voleybol branş1 düşünüldüğünde, voleybolcunun uzun boylu, sıçrama yeteneği yüksek, reaksiyon zamanı kısa, sahanın her yerinde çabuk hareket edebilme becerisi olan, yağ dokusu az, elleri büyük, pas yapabilmek için parmak ve bileklerinin kuvvetli, hareketlilik (esneklik) düzeyinin de fazla olması gerektiği bilinmektedir. Ayrıca zaman sınırlaması olmadığı için 2-3 saat süren maçlara rastlanması nedeniyle dayanıklılığının da üst düzey olması da önemlidir. Voleybolda özellikle sporcuların sıçradıktan sonra tekrar yere iniş aşamalarında dengelerini koruyabilmeleri, oyunun devamlılığ 1 , kalitesi ve sporcunun sağlığ açısından oldukça önemlidir. Denge aynı 
zamanda koordinasyonu da beraberinde getireceğinden çok daha akıcı ve aktif bir performans ortaya konmasında büyük rol alır. ${ }^{14}$ Voleybolda gövde stabilizasyonunun önemi: Spora özel aktivitelerde vücudun ilgili bölgesinin hareketi esnasında, diğer bölgelerin stabilizasyonunun sağlanmasında rol oynar. Voleybol sporunda omurganın yüksek şiddetli yüklenmelere maruz kalması gövdenin kassal fonksiyonlarının iyi geliştirilmesini gerekli hale getirmektedir. $^{15}$ Özellikle gövde kaslarının geliştirilmesinde olumlu etkilerinin olduğu bilinen pilates egzersizlerinin voleybolcuların biyomotor özelliklerinde olumlu gelişmeler meydana getirebileceği ve beraberinde oyuncuların teknik becerilerinde iyileşme gözlenebileceği düşünülmektedir.

$\mathrm{Bu}$ çalışmada pilates mat egzersizlerinin genç voleybolcularda kuvvet, dayanıklılık, sürat, patlayıcı kuvvet, süratte devamlılık, denge, esneklik özellikleri ve teknik puanları üzerine etkisinin incelenmesi amaçlanmıştır.

\section{MATERYAL ve METOT}

\section{Araştırma Grubu}

$\mathrm{Bu}$ araştırmaya 14-15 yaşlarında 5 yıl spor geçmişi olan 30 bayan voleybolcu gönüllü olarak katılmıştır. Rastgele seçimle sporculardan $15^{\prime} \mathrm{i}$ araştırma grubu(yaşları ortalamas1 15,37 $\pm 0,51 \mathrm{y} 1), 15$ 'i kontrol grubu (yaş ortalaması 15,18 $\pm 0,62$ yıl) olmuştur. Araştırmaya dahil edilecek sporcuların herhangi bir sakatlıklarının olmaması ve gönüllü olmaları şartı aranmıştır. Deney grubu ve kontrol grubunun voleybol antrenman günleri, antrenman içerikleri ve saatleri aynı olmuştur. Deney grubu ek olarak haftada iki gün birer saat pilates egzersizleri yapmıștır. Katılımcılara herhangi bir ücret ödenmemiş ve kendilerinden herhangi bir ücret alınmamıştır. Öğrencilere, ebeveynlere ve kulüp yöneticisine gönüllü olur formu imzalatılmıştır. Ayrıca sporcuların ebeveynlerine çalışmanın her aşamasında bilgi verilmiş ve izin alınmıştır. $\mathrm{Bu}$ çalışma için Sakarya Üniversitesi Tıp Fakültesi Etik Kurulundan etik kurul onayı alınmıştır.

\section{Pilates Uygulamast}

Haftada iki gün, günde bir saat toplam on iki hafta sürmüştür. Pilates egzersizleri Erenköy Kız Anadolu Lisesinin spor salonundaki pilates odasında yaptırılmıştır. Pilates egzersizleri 3 yıllık tecrübesi olan pilates eğitmeni tarafindan yaptırılmıştır.

\section{Yapılan Hareketler:}

\begin{tabular}{|c|c|c|c|}
\hline 1. Bridge & 3. Single & 4. Rolling & 5. Single Leg \\
\hline 2. Roll Up & Leg Circle & Back & Stretch \\
\hline 6. Double & 7. Single & 8. Double & \\
\hline & Straight Leg & Straight Leg & 9. Crisscross \\
\hline & Stretch & Stretch & \\
\hline 10. Side Leg & 11. Side Leg & 12. Side Leg & 13. Side Leg \\
\hline Lift & Circle & Kick & Bicycle \\
\hline 14. Side Leg & 15. Rolling & im & $17 \mathrm{D} u$ \\
\hline Banana & Like A Ball & 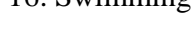 & 17.1 पsत op \\
\hline
\end{tabular}

Yukarıdaki egzersizler sırasıyla yaptırılmıştır. İlk üç hafta derslerin başında öğrencilere pilates metodu, duruşları ve beş ana prensip ögretilerek derse başlanmıştır. Üçüncü hafta itibariyle 
pilates ekipmanlarıyla varyasyonlarına geçilmiştir. Dersler haftanın Salı ve Perşembe günleri 17:00 ile 18:00 arası yaptırılmıştır.

\section{Verilerin Toplanmast}

Antropometrik ölçümler (boy, vücut ağırlığı, tek kol uzunluğu, çift kol uzunluğu, kulaç uzunluğu, vücut kütle indeksi), denge testi, ısınma, otur eriş testi, omuz esneklik testi, durarak uzun atlama, dikey sıçrama (aktif), dikey sıçrama (pasif), Kol hareket sürati, el kavrama kuvveti, sağlık topu atma, Bükülü kol testi, line drill testi, 30 saniye mekik (gövde kuvveti), mekik koşusu ölçümleri voleybol sahasında gerçekleştirilmiştir. Ölçümlere antropometrik ölçümlerle başlanmıştır. Testler voleybol kulübünün dört antrenörü, iki beden eğitimi öğretmeni ve üç pilates eğitmeni tarafından gerçekleştirilmiştir. Her öğrencinin elinde kendi bilgileri olan ve yapacağı testlerin olduğu bir form verilmiştir. Teknik performans ölçümleri bir sonraki gün aynı salonda gerçekleştirilmiştir. Kontrol ve deney gurubuna 12 haftalık antrenmanların öncesinde ve sonrasında testler tekrar uygulanmıştır.

Antropometrik Ölçümler; Boy uzunluğu, tek kol uzunluğu, çift kol uzunluğu ve kulaç uzunluğu değerleri $0.5 \mathrm{~cm}$ hassasiyette stadiometre ile ölçülmüştür. Deneklerin vücut ağırlıkları ise 0,1 kg hassasiyetli OMRON marka baskül ile ölçülmüştür.

Denge Performansi; Denek tercih edeceği ayağıyla $50 \times 4 \times 5 \mathrm{~cm}$ ölçülerindeki kirişin uzun kısmının üstünde olabildiğince uzun süre durmaya çalışmıştır. $\mathrm{Bu}$ arada serbest kalan ayağını dengede kalan ayağının diz kısmına değecek şekilde bükerek, elleri belinde durmaya çalışmıştır. Denge pozisyonunda geçen süre kronometre ile ölçülmüştür.

Esneklik; Gövde esnekliği için otur eriş testi ${ }^{16}$ ve üst ekstremite esnekliği değerlendirmek için omuz esneklik testi ${ }^{17}$ uygulanmıştır.

Patlayıcı Kuvvet; Yatay Sıçrama (durarak uzun atlama), Squat Jump (pasif) sıçrama ve Counter Movement Jump (aktif) siçrama testleri uygulanmıştır. Siçrama yüksekliklerinin belirlenmesinde "My Jump" uygulaması kullanılmıştır. ${ }^{18}$

Üst Ekstremite Sürati; Üst ekstremite hareket süratinin değerlendirilmesinde kol hareket sürati testi uygulanmıştır. ${ }^{16}$

Süratte Devamlılık; Süratte devamlılık özelliğinin belirlenmesinde, voleybol saha ölçülerinden faydalanarak $6 \mathrm{~m}, 9 \mathrm{~m}$ ve $18 \mathrm{~m}$ mesafeler ile line drill testi uygulanmıştır.

El kavrama kuvveti; Dominant ele ait el kavrama kuvveti değerleri Takei marka el dinamometresi ile ölçülmüştür.

Üst gövde elastik kuvveti; Üst gövde kuvvetini değerlendirmek amacıyla sağlık topu firlatma testi uygulanmıştır. Denekler belirlenen çizgide dizlerinin üzerinde vücut dik pozisyonda, sağlık topunu $(2 \mathrm{~kg})$ firlatma mesafeleri ölçülmüştür. 
Üst ekstremite kuvvet devamlı̆gl; Üst gövde kuvvet devamlığ 1 özelliğinin değerlendirilmesinde bükülü kol asılma testi uygulanmıştır. ${ }^{16}$

Gövde kuvveti; Gövde kuvvetinin değerlendirilmesinde 30 saniye mekik testi uygulanmıştır. Klasik mekik pozisyonu (ayaklar yerde, dizler bükülü, eller başın arkasında), "Hazır... Başla" işaretiyle başlamışlardır ve 30 saniye içerisinde gerçekleştirilen nizami mekik sayısı ölçülmüştür.

Dayanıklılık; Dayanıklılığın değerlendirilmesi amacıyla deneklere 20 metre standart mekik koşusu testi uygulanmıştır. ${ }^{16}$

\section{Teknik Performansının Değerlendirilmesi;}

Servis, manşet ve smaç tekniklerine ait belirlenen teknik bileșenler 3 eğitmen tarafından 1-5 arasinda verilen puanlar ile değerlendirilmiştir.

Servis performansının değerlendirilmesi;

a) Duruş, b) Topu doğru noktaya atma, c) Topa doğru vuruş şekli, d) Hedefe atış

Manşet performansının değerlendirilmesi;

a) Vücut pozisyonu, b) Kolların duruşu, c) Vücudun dönüş yönü, d) Hedefe manşet

Smaç performansının değerlendirilmesi;

a) Adımlama, b) Topla yukarda buluşma anı, c) Ağırlık aktarımı, d) Hedef nokta

\section{Verilerin Analizi}

Çalışmanın istatiksel analizi $\mathrm{R}$ istatistik paket programı kullanılarak yapılmıştır. Verilerin homojen olup olmadıklarını belirlemek için Chi Square (ki kare) Homojenity testi kullanılmıştır. Homojen veriler için two sample paired t-test , homojen olmayan veriler için ve $n$ sayısı 15 olduğu için Wilcoxon Signed Rank Test parametrik olmayan testi kullanılmıştır. Tüm istatistiklerdeki $\mathrm{p}$ anlamlılık değeri $\mathrm{p} \leq 0.05$ olarak alınmıștır.

\section{BULGULAR}

Deney gurubu ve kontrol gurubunun ön test değerlerine uygulanan ki kare homojenite testinin sonucunda antropometrik özellikler ve biyomotor testler homojen teknik performanslar homojen olamayan dağılım gösterdiği gözlenmiştir. Kontrol ve deney grubu olarak belirlenen her iki grubun ön test değerleri arasında anlamlı farklılık olmadığı gözlenmiştir $(p>0.05)$

Tablo 1. Kontrol Grubunun Biyomotor Özellikler Ön test - Son test Değerlerinin Karşılaştırılması

\begin{tabular}{|c|c|c|c|c|}
\hline \multirow{3}{*}{ Parametreler } & \multicolumn{4}{|c|}{ Kontrol Gurubu $\mathrm{n}=15$} \\
\hline & Ön Test & Son Test & & \\
\hline & Ortalama \pm SD & Ortalama \pm SD & Fark $\%$ & $P$ \\
\hline Vücut Ağgurlắı (kg) & $60.7 \pm 10.27$ & $61.7 \pm 10.14$ & 1.7 & 0.0003 \\
\hline Vücut Kütle Indeksi $\left(\mathrm{kg} / \mathrm{m}^{2}\right)$ & $21.2 \pm 3.26$ & $21.6 \pm 3.22$ & 1.8 & 0.0002 \\
\hline Denge Testi (sa) & $5.1 \pm 2.72$ & $5.1 \pm 2.31$ & -1.2 & 0.8821 \\
\hline Otur Eriş $(\mathrm{cm}$ ) & $29 \div 9.04$ & $29 \pm 9.09$ & 0.0 & 0.5711 \\
\hline Omuz Esneklik $(\mathrm{cm})$ & $70 \pm 10.41$ & $70 \pm 10.09$ & 0.0 & 0.9232 \\
\hline Durarak Uzun Atlama $(\mathrm{cm})$ & $1.67 \pm 0.25$ & $1.68 \pm 0.25$ & 0.6 & 0.0848 \\
\hline Dikey Stçrama. Aktif (cm) & $39 \pm 4.55$ & $40 \pm 3.69$ & 2.6 & 0.0664 \\
\hline Dikey Stçrama Pasif $(\mathrm{cm})$ & $33 \pm 4.27$ & $33 \pm 2.62$ & 0.0 & 0.5397 \\
\hline Kol Hareket Sürati (sp) & $13.2 \pm 1.58$ & $12.4 \pm 1.37$ & -6.0 & 0.0065 \\
\hline E1 Kavrama Kuvveti (kgfo & $24.67 \pm 2.79$ & $25.95 \div 2.87$ & 5.2 & 0.0001 \\
\hline Sağluk Topu Atma (m) & $4.31 \pm 0.71$ & $4.64 \pm 0.78$ & 7.7 & 0.0058 \\
\hline Bükülü Kol (sn) & $1.13 \pm 1.19$ & $1.33 \pm 1.35$ & 17.7 & 0.1887 \\
\hline Line Driill(sa) & $17.5 \pm 1.40$ & $14.6 \pm 1.42$ & -16.6 & 0.0001 \\
\hline Mekikik Görde (telkrar) & $22 \pm 4.33$ & $22 \pm 4.25$ & 0.0 & 0.0961 \\
\hline Mekik Kogousu (mekik) & $36 \pm 8.25$ & $41 \pm 10.45$ & 13.9 & 0.0015 \\
\hline
\end{tabular}


Tablo 2. Kontrol Grubunun Teknik Performans

Ön test - Son test Değerlerinin Karşılaştırılması

\begin{tabular}{|c|c|c|c|c|}
\hline \multirow{3}{*}{ Parametreler } & \multicolumn{4}{|c|}{ Kontrol Gurubu Teknik Puanlar $\mathrm{n}=15$} \\
\hline & Ön Test & Son Test & Fark \% & P \\
\hline & Ortalama \pm SD & Ortalama \pm SD & ats & 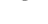 \\
\hline Servis durugüu & $3.33 \pm 0.62$ & $4.33 \pm 0.49$ & 30.0 & 0.0047 \\
\hline Servis topu doğ́ru noltaya atma & $2.53 \pm 0.64$ & $3.87 \pm 0.64$ & 53.0 & 0.0008 \\
\hline Servis topa doğnu vuruş & $3.00 \pm 0.53$ & $3.87 \pm 0.64$ & 29.0 & 0.0034 \\
\hline Servis hedefe atts & $2.33=0.49$ & $3.53 \pm 0.74$ & 51.5 & 0.0009 \\
\hline Manșet vücut pozisyonu & $3.27 \pm 0.46$ & $4.27 \pm 0.59$ & 30.6 & 0.0028 \\
\hline Manşet kollarm duruşu & $2.60 \pm 0.63$ & $3.93 \pm 0.59$ & 51.2 & 0.0020 \\
\hline 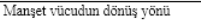 & $3.20 \pm 0.56$ & $4.13 \pm 0.35$ & 29.1 & 0.0025 \\
\hline Manşet hedefe manş̧et & $2.67 \pm 0.62$ & $3.80 \pm 0.41$ & 42.3 & 0.0029 \\
\hline Smaç admlama & $3.47 \pm 0.52$ & $4.40 \pm 0.51$ & 26.8 & 0.0046 \\
\hline Smaç topla yukarda buluṣma anı & $3.13 \pm 0.64$ & $4.27 \pm 0.46$ & 36.4 & 0.0010 \\
\hline Smaç ağrrlik altarm1 & $2.60 \pm 0.51$ & $3.73 \pm 0.46$ & 43.5 & 0.0029 \\
\hline Smaç hedef nokta & $2.53 \pm 0.64$ & $3.87 \pm 0.64$ & 53.0 & 0.0017 \\
\hline
\end{tabular}

Tablo 3. Deney Grubunun Biyomotor Özellikler Ön test - Son test Değerlerinin Karşılaştırılması

\begin{tabular}{|c|c|c|c|c|}
\hline \multirow{3}{*}{ Parametreler } & \multicolumn{4}{|c|}{ Deney Gurubu $\mathrm{n}=15$} \\
\hline & \multirow{2}{*}{$\begin{array}{c}\text { Ön Test } \\
\text { Ortalama } \pm \text { SD }\end{array}$} & \multirow{2}{*}{$\begin{array}{c}\text { Son Test } \\
\text { Ortalama } \pm \text { SD }\end{array}$} & \multirow{2}{*}{ Fark \% } & \multirow{2}{*}{$P$} \\
\hline & & & & \\
\hline Vücut Ag̈rrliğ (kg) & $60.8 \pm 8.26$ & $60.5 \pm 7.98$ & -0.5 & 0.1964 \\
\hline Vücut Kütle Indelsi $\left(\mathrm{kg} \mathrm{m} \mathrm{m}^{2}\right)$ & $21.2 \pm 2.27$ & $21.12 \pm 2.20$ & -0.4 & 0.2126 \\
\hline Denge Testi ( $(\mathrm{s} n)$ & $5.5 \pm 2.26$ & $23.4 \pm 19.04$ & 327.8 & 0.0019 \\
\hline Otur Eris $(\mathrm{cm})$ & $26=601$ & $40 \pm 4.90$ & 53.9 & 0.0001 \\
\hline Omuz Esneklilik $(\mathrm{cm})$ & $80=18.46$ & $62 \pm 12.44$ & -22.5 & 0.0001 \\
\hline D.U. Atlama $(\mathrm{cm})$ & $1.79 \pm 0.18$ & $1.86 \pm 0.18$ & 3.9 & 0.0001 \\
\hline D. Suc Alktif $(\mathrm{cm})$ & $39=3.44$ & $42 \pm 5.28$ & 7.7 & 0.0001 \\
\hline D. Suc Pasif $(\mathrm{cm})$ & $32 \pm 3.25$ & $34 \pm 3.41$ & 6.3 & 0.0037 \\
\hline Kol H. Sürati (sn) & $13.2 \pm 1.09$ & $10.8 \pm 0.92$ & -18.3 & 0.0001 \\
\hline El K. Kurveti (kgt) & $26.49 \pm 6.07$ & $31.65 \div 5.48$ & 19.5 & 0.0001 \\
\hline S. Topu Atma (m) & $4.62 \pm 0.84$ & $6.33 \pm 0.90$ & 37.0 & 0.0001 \\
\hline Bükülü Kol (sn) & $1.6 \pm 1.76$ & $3.1 \pm 2.03$ & 95.6 & 0.0001 \\
\hline Linele Drillo (sn) & $17.0 \pm 1.42$ & $11.5=1.47$ & -32.8 & 0.0001 \\
\hline Melaklk Görde (telrar) & $24=3.32$ & $30 \pm 1.93$ & 25.0 & 0.0001 \\
\hline Melikik Kogusu (mekik) & $37=11.26$ & $56=14.90$ & 51.4 & 0.0001 \\
\hline
\end{tabular}

Tablo 4. Deney Grubunun Teknik Performans Ön test - Son test Değerlerinin Karşılaştırılması

\begin{tabular}{|c|c|c|c|c|}
\hline \multirow{3}{*}{ Parametreler } & \multicolumn{4}{|c|}{ Deney Gurubu Teknik Puanlar $\mathrm{n}=15$} \\
\hline & On Test & Son Test & For 06 & P \\
\hline & Ortalama \pm SD & Ortalama \pm SD & Fark $\%$ & P \\
\hline Servis durug̣u & $3.27 \pm 0.59$ & $4.53 \pm 0.52$ & 38.5 & 0.0012 \\
\hline Servis topu doğnu nolktaya atma & $2.67 \pm 0.72$ & $4.13 \pm 0.35$ & 54.7 & 0.0008 \\
\hline Servis topa doğru vuruş & $3.13 \pm 0.64$ & $4.13 \pm 0.74$ & 31.2 & 0.0003 \\
\hline Servis hedefe aths & $2.33 \pm 0.49$ & $3.60 \pm 0.74$ & 54.5 & 0.0005 \\
\hline Manget vücut pozisyonu & $3.40 \pm 0.51$ & $4.40 \pm 0.63$ & 29.4 & 0.0028 \\
\hline Manģet kollarn duruşu & $2.60 \pm 0.63$ & $3.93 \pm 0.59$ & 51.2 & 0.0020 \\
\hline Manget vücudun dönüs yờnü & $3.40 \pm 0.63$ & $4.40 \pm 0.51$ & 29.4 & 0.0047 \\
\hline Manşet hedefe manşet & $2.67 \pm 0.62$ & $4.07 \pm 0.70$ & 52.4 & 0.0019 \\
\hline Smaç adımlama & $3.47 \pm 0.52$ & $4.60 \pm 0.51$ & 32.6 & 0.0019 \\
\hline Smaç topla yukarda buluşma anı & $3.27 \pm 0.70$ & $4.53 \pm 0.52$ & 38.5 & 0.0004 \\
\hline Smaç ağırlık altarımı & $2.60 \pm 0.51$ & $4.07 \pm 0.70$ & 56.5 & 0.0012 \\
\hline Smaç hedef nokta & $2.67 \pm 0.82$ & $4.47 \pm 0.64$ & 67.4 & 0.0006 \\
\hline
\end{tabular}

\section{TARTIŞMA VE SONUÇ}

$\mathrm{Bu}$ araştırma; pilates mat egzersizlerinin genç voleybolcularda kuvvet, dayanıklılık, sürat, patlayıcı kuvvet, süratte devamlılık, denge ve esneklik parametreleri ile teknik performansları üzerine etkisini belirlemek amacı ile yapılmıştır. Kontrol gurubu verileri incelendiğinde kol hareket sürati, line drill, el kavrama kuvveti, sağlık topu atma ve mekik koşusu testlerinde istatistiksel olarak pozitif yönde anlamlı fark bulunmuş olup denge testi, otur eriş, omuz esneklik, durarak uzun atlama, dikey sıçrama aktif, dikey sıçrama pasif, bükülü kol asılma ve 30 saniye mekik testlerinde istatistiksel olarak anlamlı bir fark bulunamamıştır (Tablo 1). Deney gurubuna bakıldığında tüm bu testlerde istatistiksel olarak pozitif yönde anlamlı fark bulunmuştur (Tablo 3). Deney ve kontrol guruplarının pozitif yönde anlamlı fark bulunan verilerinin son testleri karşılaştırıldığında deney gurubundaki gelişmenin daha yüksek olduğu gözlenmiştir. Teknik performans değerlerinde deney ve kontrol gurup verilerinin hepsinde benzer şekilde, istatistiksel olarak pozitif yönde anlamlı fark oluştuğu gözlenmiştir (Tablo2, Tablo 4).

Pilates ve kuvvet üzerine etkileri üzerine yapılan çalışmalarda, uzun süreli direnç egzersizlerinin kuvvette artışa neden olduğu gözlenmiştir. Yaşlılara uygulanan direnç egzersizlerinde daha çok büyük kas grupları ele alındığı çalışmada, direnç egzersizleri sonrasında kas kuvveti ve kemik mineral 
yoğunluğunda istatistiksel olarak anlamlı değişimler saptanmıştır. ${ }^{12}$ Emery ve ark. 19 kişilik denek gurubu ile (9 kontrol, 10 deney) 12 hafta süreyle haftada 2 defa, 1 er saatlik pilates çalışması yaptırmıştır ve abdominal kuvvet, üst vücut postürü ve vücut esnekliğinde olumlu yönde artış gözlemlemişlerdir. ${ }^{4}$ Duncan ve ark. ise, 34 denek ile haftada 2 gün 8 hafta süreyle minderde pilates egzersizleri uygulamışlar ve transversus abdominus ve internal oblik kaslarının aktivitesinde artış gözlemişlerdir. ${ }^{5}$

Bir çalışmada 25-65 yaş arası, 50 bireyi iki guruba ayırmış, 25 kişiye pilates egzersizleri uygulamıştır. Pilatesin kas enduransı, esnekliği, denge ve postür üzerine etkisini araştırdığ 1 çalışmasında, pilatesin kas enduransı ve esnekliği üzerine istatistiksel olarak anlamlı artışa yol açtığ1 gözlenirken denge ve postür üzerine anlamlı bir gelişme görülememiştir. ${ }^{11}$

Kloubec, haftada 2 gün 12 haftalık pilates egzersizi uyguladığı gurupta, abdominal ve üst ekstremite kas dayanıklılığının anlamlı şekilde arttığını gözlemiştir. ${ }^{11}$ Yine Rogers ve ark. 8 haftalık minderde yapılan pilates eğitimi sonrası gövde kas dayanıklılığında istatistiksel olarak anlamlı bir artış olduğunu belirlemişlerdir. ${ }^{9}$ S1kl1kla sedanter bireyler üzerinde gerçekleştirilen çalışmaların yanında tenisçilerde yapılan bir çalışmada, 6 haftalık minderde yapılan pilates eğitimi sonrası tenis servis hızı ve abdominal kas dayanıklılığında artış olduğu gözlenmiştir. ${ }^{19}$ Duncan ve ark. ise dayanıklılık testi olarak mekik testi kullanmışlar ve kontrol ve deney gurubunda pozitif yönde istatistiksel olarak artış gözlemekle birlikte deney gurubundaki artış miktarının daha yüksek olduğunu belirlemişlerdir. ${ }^{5}$

Pilates ile ilgili olarak gerçekleştirilen çalışmalarda, özellikle gövde kasları kuvveti ve dayanıklılığında gözlenen artışa benzer şekilde bu çalışmada da pilates uygulamasının Voleybol oyuncuları kas kuvveti ve dayanıklılık özelliklerinde artışa neden olduğu belirlenmiştir.

Kuvvet özelliğinin yanında, birçok çalışmada pilates egzersizlerinin esneklik ve denge özelliklerinde olumlu etkilerde bulunduğu gözlenmiştir. Sedanter bayanlar üzerinde yapılan araştırmada modern pilates egzersizlerinin abdominal ve bel bölgesi esnekliğini geliştirdiği görülmüştür. ${ }^{10}$ Irez ve ark. deneklere 12 hafta, haftada 3 gün 1 er saat pilates egzersizleri uygulatmış ve pilates yapanların, yapmayanlara göre denge, esneklik, vücut tepki süresi, kas kuvveti değerlerinde daha yüksek gelişim gösterdiklerini gözlemlemişlerdir. ${ }^{6}$ Bir başka çalışmada 31 erkek ve kadında (65-85 yaş arası) pilatesin statik ve dinamik denge üzerine etkisini araştırılmıştır. 10 haftalık çalışma sonucunda istatistiksel olarak ilk ve son testler karşılaştırıldığında anlamlı fark bulunmuştur. ${ }^{7}$ Sewright ve ark. pilates egzersizlerinin denge performans üzerinde etkilerini araştırmak üzere yaptıkları çalışmada kontrol gurubunda anlamlı bir fark bulunmazken, deney gurubunda pozitif yönde anlamlı farklılık oluştuğunu 
gözlemişlerdir. ${ }^{19}$ Segal ve ark. 31 yetişkin bayan ile gerçekleştirdikleri çalışmada, haftada 1 saat ve 6 ay süreyle pilates egzersizi uygulamasının esneklik sonuçlarında anlamlı bir artış neden olduğunu belirtmişlerdir. ${ }^{8}$ Kloubec ve ark. çalışmasında da benzer biçimde pilates mat egzersizlerinin sportif performansın gelişimine yardımcı olan denge ve esneklik değerlerini iyileştirdiği gözlenmiştir. ${ }^{11}$

Pilates ile ilgili olarak gerçekleştirilen çalışmalarda gözlenen değişimlere benzer şekilde bu çalışmada da pilates uygulamasının Voleybol oyuncuları esneklik ve denge özelliklerinde olumlu artışa neden olduğu gözlenmiştir.

Pilates egzersizlerinin vücut kompozisyonu üzerindeki etkileri üzerine yapılan çalışmalarda, vücut ağırlığı ve yağ yüzdesinde belirgin bir değişiklik meydana gelmediği gözlenmiştir. ${ }^{8},{ }^{10}$ Bu çalışma da kontrol gurubu VKI değerlerinde anlamlı bir artış olmakla birlikte deney gurubunda anlamlı bir değişiklik gözlenmemiştir.

Kontrol ve deney gurubu teknik puanlar değerlendirildiğinde her iki gurupta da benzer biçimde anlamlı bir gelişme oluştuğu gözlenmiştir. Pilates egzersizlerinin biyomotor özellikler üzerinde neden olduğu gelişmenin kontrol gurubu ile karşılaştırılmasında 5 lik puanlamanın yeterli hassasiyette değerlendirme yapmaya olanak vermediği düşünülmektedir.

\section{ÖNERÍLER}

Sonuç olarak 12 haftalık pilates mat egzersizinin 14-15 yaş voleybol kız öğrencilerinin bazı biyomotor özellikler ve teknik performanslarında olumlu etkilerde bulunduğu görülmüştür. Sedanter bireylerin yanında aktif sporcularda da pilates egzersizlerinin performansin arttırılmasında faydalı olacağı düşünülmektedir.

\section{KAYNAKLAR}

1. http://www.pilatesbaps.com/blog.php?blogId $=1$ (Son Erişim: 20. 07. 2016).

2. https://tr.wikipedia.org/wiki/Pilates

(Son Erişim: 21.07.2016).

3. https://www.statista.com/statistics/191616/pa rticipants-in-pilates-training-in-the-us-since2006/ (Son Erişim: 01.12.2016).

4. Emery K. De Serres SJ. McMillan A. Côté JN. The effects of a Pilates training program on arm-trunk posture and movement. Clinical Biomechanics, 2009; 25(2):124-130.

5. Duncan JC, Pierson Z, Battersby G. Effect of pilates mat exercises and conventional exercise programmers on transversus abdominus and obliquus internus activity: Pilot randomized trial. Manuel Therapy, 2011; 16: 183-189

6. Irez BG, Ozdemir RA, Evin R, Irez SG, Korkusuz F. Integrating pilates exercise into an exercise program for $65+$ year-old women to reduce falls. J Sports Sci Med, 2009; 10(1): $105-111$. 
7. Hall DW. The effect of Pilates-Based Training on Balance and Gait in an Elderly Population. Master Thesis. Sandiago: Sandiago State University Department of Exercise and Nutritional Sciences; 1998.

8. Segal NA, Hein J, Basford JR. The effects of pilates training on flexibility and body composition: An observational study, Archives of Physical Medicine and Rehabilitation, 2004; 85(12): 1977-1981.

9. Rogers K, Gibson AL. Eight-Week Traditional Mat Pilates Training-Program Effects on Adult Fitness Characteristics. Research Quarterly for Exercise and Sport, 2009; 80 (3): 596-574.

10. Sekendiz B, Özkan A, Korkusuz F, Akın S. Effects of Pilates exercise on trunk strength, endurance and flexibility in sedentary adult females. Journal of Bodywork and Movement Therapies, 2007; 11(4): 318-326.

11. Kloubec JA. Pilates for Improvement of Muscle Endurance Flexibility, Balance and Postur, PubMed, US. National Library of Medicine National Institutes of Health. 2010; 24(3): 661-667

doi:

10.1519/JSC.Ob013e3181c277a6.

12. Rhodes RE, Martin DA, Taunton JE, Rhodes EC, Donelly M, Elliot J. Factors associated with exercise adherence among older adults: an individual perspective. Sports Med. 1999; 28, 397-411.

\section{3. http://fitnessegitmeni.com/pilates-}

\section{yoga/pilates-nedir-kimler-pilates-yapabilir/}

(Son Erişim: 21.07.2016).

14. Günay AR. 14-16 yaş erkek voleybolcuların fiziksel antropometrik ve motorik özelliklerinin incelenmesi. Gazi Ünüversitesi, Sağlık Bilimleri Enstitüsü Yüksek lisans tezi, Ankara, Danışman: Prof. Dr. G. Kadir; 2013. 15. http://www.openaccess.hacettepe.edu.tr:808 0/xmlui/bitstream/handle/11655/1624/88ac14 e4-c4f0-4ea4-a6a7ecd3786a495d.pdf?sequence=1 (Son Erişim: 29.07.2016).

16. Eurofit, (1993), Eurofit Tests of Physical Fitness, 2nd Edition, Strasbourg.

\section{7. http://www.topendsports.com/testing/tests/sh} oulder-flex.htm (Son Erişim: 01.12.2016).

18. Carlos Balsalobre-Fernández, Mark Glaister \& Richard Anthony Lockey. The validity and reliability of an iPhone app for measuring vertical jump performanc Journal of Sports Sciences. 2015; 33(15); 1574-1579.

19. Sewright K, Martens DW, Axtell Facsm RS, Rinehardt, K. F. Effects of Six Weeks of Pilates Mat Training on Tennis Serve Velocity, Muscular Endurance, and Their Relationship in Collegiate Tennis Players. Medicine \& Science in Sports \& Exercise, 2004; 36 (5): 167. 
Tablo 1. Kontrol Grubunun Biyomotor Özellikler Ön test - Son test Değerlerinin Karşılaştırılması

\begin{tabular}{|c|c|c|c|c|}
\hline \multirow{3}{*}{ Parametreler } & \multicolumn{4}{|c|}{ Kontrol Gurubu n=15 } \\
\hline & Ön Test & Son Test & \multirow{2}{*}{ Fark \% } & \multirow{2}{*}{$\mathbf{P}$} \\
\hline & Ortalama \pm SD & Ortalama \pm SD & & \\
\hline Vücut Ağırlığg $1(\mathrm{~kg})$ & $60.7 \pm 10.27$ & $61.7 \pm 10.14$ & 1.7 & 0.0003 \\
\hline Vücut Kütle İndeksi $\left(\mathrm{kg} / \mathrm{m}^{2}\right)$ & $21.2 \pm 3.26$ & $21.6 \pm 3.22$ & 1.8 & 0.0002 \\
\hline Denge Testi (sn) & $5.1 \pm 2.72$ & $5.1 \pm 2.31$ & -1.2 & 0.8821 \\
\hline Otur Eriş (cm) & $29 \pm 9.04$ & $29 \pm 9.09$ & 0.0 & 0.5711 \\
\hline Omuz Esneklik (cm) & $70 \pm 10.41$ & $70 \pm 10.09$ & 0.0 & 0.9232 \\
\hline Durarak Uzun Atlama (cm) & $1.67 \pm 0.25$ & $1.68 \pm 0.25$ & 0.6 & 0.0848 \\
\hline Dikey Sıçrama. Aktif (cm) & $39 \pm 4.55$ & $40 \pm 3.69$ & 2.6 & 0.0664 \\
\hline Dikey Sıçrama Pasif (cm) & $33 \pm 4.27$ & $33 \pm 2.62$ & 0.0 & 0.5397 \\
\hline Kol Hareket Sürati (sn) & $13.2 \pm 1.58$ & $12.4 \pm 1.37$ & -6.0 & 0.0065 \\
\hline El Kavrama Kuvveti (kgf) & $24.67 \pm 2.79$ & $25.95 \pm 2.87$ & 5.2 & 0.0001 \\
\hline Sağlık Topu Atma (m) & $4.31 \pm 0.71$ & $4.64 \pm 0.78$ & 7.7 & 0.0058 \\
\hline Bükülü Kol (sn) & $1.13 \pm 1.19$ & $1.33 \pm 1.35$ & 17.7 & 0.1887 \\
\hline Line Drill (sn) & $17.5 \pm 1.40$ & $14.6 \pm 1.42$ & -16.6 & 0.0001 \\
\hline Mekik Gövde (tekrar) & $22 \pm 4.33$ & $22 \pm 4.25$ & 0.0 & 0.0961 \\
\hline Mekik Koşusu (mekik) & $36 \pm 8.25$ & $41 \pm 10.45$ & 13.9 & 0.0015 \\
\hline
\end{tabular}


Tablo 2. Kontrol Grubunun Teknik Performans Ön test - Son test Değerlerinin Karşılaştırılması

\begin{tabular}{|c|c|c|c|c|}
\hline \multirow{3}{*}{ Parametreler } & \multicolumn{4}{|c|}{ Kontrol Gurubu Teknik Puanlar n=15 } \\
\hline & Ön Test & Son Test & \multirow{2}{*}{ Fark \% } & \multirow{2}{*}{$\mathbf{P}$} \\
\hline & Ortalama \pm SD & Ortalama \pm SD & & \\
\hline Servis duruşu & $3.33 \pm 0.62$ & $4.33 \pm 0.49$ & 30.0 & 0.0047 \\
\hline Servis topu doğru noktaya atma & $2.53 \pm 0.64$ & $3.87 \pm 0.64$ & 53.0 & 0.0008 \\
\hline Servis topa doğru vuruş & $3.00 \pm 0.53$ & $3.87 \pm 0.64$ & 29.0 & 0.0034 \\
\hline Servis hedefe atış & $2.33 \pm 0.49$ & $3.53 \pm 0.74$ & 51.5 & 0.0009 \\
\hline Manşet vücut pozisyonu & $3.27 \pm 0.46$ & $4.27 \pm 0.59$ & 30.6 & 0.0028 \\
\hline Manşet kolların duruşu & $2.60 \pm 0.63$ & $3.93 \pm 0.59$ & 51.2 & 0.0020 \\
\hline Manşet vücudun dönüş yönü & $3.20 \pm 0.56$ & $4.13 \pm 0.35$ & 29.1 & 0.0025 \\
\hline Manşet hedefe manşet & $2.67 \pm 0.62$ & $3.80 \pm 0.41$ & 42.3 & 0.0029 \\
\hline Smaç adımlama & $3.47 \pm 0.52$ & $4.40 \pm 0.51$ & 26.8 & 0.0046 \\
\hline Smaç topla yukarda buluşma anı & $3.13 \pm 0.64$ & $4.27 \pm 0.46$ & 36.4 & 0.0010 \\
\hline Smaç ağırlık aktarımı & $2.60 \pm 0.51$ & $3.73 \pm 0.46$ & 43.5 & 0.0029 \\
\hline Smaç hedef nokta & $2.53 \pm 0.64$ & $3.87 \pm 0.64$ & 53.0 & 0.0017 \\
\hline
\end{tabular}


Tablo 3. Deney Grubunun Biyomotor Özellikler Ön test - Son test Değerlerinin Karşılaştırılması

\begin{tabular}{|c|c|c|c|c|}
\hline \multirow{3}{*}{ Parametreler } & \multicolumn{4}{|c|}{ Deney Gurubu n=15 } \\
\hline & Ön Test & Son Test & \multirow{2}{*}{ Fark \% } & \multirow{2}{*}{$\mathbf{P}$} \\
\hline & Ortalama \pm SD & Ortalama \pm SD & & \\
\hline Vücut Ağırlığg (kg) & $60.8 \pm 8.26$ & $60.5 \pm 7.98$ & -0.5 & 0.1964 \\
\hline Vücut Kütle İndeksi $\left(\mathrm{kg} / \mathrm{m}^{2}\right)$ & $21.2 \pm 2.27$ & $21.12 \pm 2.20$ & -0.4 & 0.2126 \\
\hline Denge Testi (sn) & $5.5 \pm 2.26$ & $23.4 \pm 19.04$ & 327.8 & 0.0019 \\
\hline Otur Eris $(\mathrm{cm})$ & $26 \pm 6.1$ & $40 \pm 4.90$ & 53.9 & 0.0001 \\
\hline Omuz Esneklik (cm) & $80 \pm 18.46$ & $62 \pm 12.44$ & -22.5 & 0.0001 \\
\hline D.U. Atlama $(\mathrm{cm})$ & $1.79 \pm 0.18$ & $1.86 \pm 0.18$ & 3.9 & 0.0001 \\
\hline D. Siç. Aktif (cm) & $39 \pm 3.44$ & $42 \pm 5.28$ & 7.7 & 0.0001 \\
\hline D. Sıç. Pasif $(\mathrm{cm})$ & $32 \pm 3.25$ & $34 \pm 3.41$ & 6.3 & 0.0037 \\
\hline Kol H. Sürati (sn) & $13.2 \pm 1.09$ & $10.8 \pm 0.92$ & -18.3 & 0.0001 \\
\hline El K. Kuvveti (kgf) & $26.49 \pm 6.07$ & $31.65 \pm 5.48$ & 19.5 & 0.0001 \\
\hline S. Topu Atma (m) & $4.62 \pm 0.84$ & $6.33 \pm 0.90$ & 37.0 & 0.0001 \\
\hline Bükülü Kol (sn) & $1.6 \pm 1.76$ & $3.1 \pm 2.03$ & 95.6 & 0.0001 \\
\hline Line Drill (sn) & $17.0 \pm 1.42$ & $11.5 \pm 1.47$ & -32.8 & 0.0001 \\
\hline Mekik Gövde (tekrar) & $24 \pm 3.32$ & $30 \pm 1.93$ & 25.0 & 0.0001 \\
\hline Mekik Koşusu (mekik) & $37 \pm 11.26$ & $56 \pm 14.90$ & 51.4 & 0.0001 \\
\hline
\end{tabular}


Tablo 4. Deney Grubunun Teknik Performans Ön test - Son test Değerlerinin Karşılaştırılması

\begin{tabular}{|c|c|c|c|c|}
\hline \multirow{3}{*}{ Parametreler } & \multicolumn{4}{|c|}{ Deney Gurubu Teknik Puanlar n=15 } \\
\hline & Ön Test & Son Test & \multirow{2}{*}{ Fark \% } & \multirow{2}{*}{$\mathbf{P}$} \\
\hline & Ortalama \pm SD & Ortalama \pm SD & & \\
\hline Servis duruşu & $3.27 \pm 0.59$ & $4.53 \pm 0.52$ & 38.5 & 0.0012 \\
\hline Servis topu doğru noktaya atma & $2.67 \pm 0.72$ & $4.13 \pm 0.35$ & 54.7 & 0.0008 \\
\hline Servis topa doğru vuruş & $3.13 \pm 0.64$ & $4.13 \pm 0.74$ & 31.2 & 0.0003 \\
\hline Servis hedefe atış & $2.33 \pm 0.49$ & $3.60 \pm 0.74$ & 54.5 & 0.0005 \\
\hline Manşet vücut pozisyonu & $3.40 \pm 0.51$ & $4.40 \pm 0.63$ & 29.4 & 0.0028 \\
\hline Manşet kolların duruşu & $2.60 \pm 0.63$ & $3.93 \pm 0.59$ & 51.2 & 0.0020 \\
\hline Manşet vücudun dönüş yönü & $3.40 \pm 0.63$ & $4.40 \pm 0.51$ & 29.4 & 0.0047 \\
\hline Manşet hedefe manşet & $2.67 \pm 0.62$ & $4.07 \pm 0.70$ & 52.4 & 0.0019 \\
\hline Smaç adımlama & $3.47 \pm 0.52$ & $4.60 \pm 0.51$ & 32.6 & 0.0019 \\
\hline Smaç topla yukarda buluşma anı & $3.27 \pm 0.70$ & $4.53 \pm 0.52$ & 38.5 & 0.0004 \\
\hline Smaç ağırlık aktarımı & $2.60 \pm 0.51$ & $4.07 \pm 0.70$ & 56.5 & 0.0012 \\
\hline Smaç hedef nokta & $2.67 \pm 0.82$ & $4.47 \pm 0.64$ & 67.4 & 0.0006 \\
\hline
\end{tabular}

